\title{
Pectolinarigenin inhibits non-small cell lung cancer progression by regulating the PTEN/PI3K/AKT signaling pathway
}

\author{
FEI XU ${ }^{1}$, XUAN GAO $^{2}$ and HUIYUN PAN ${ }^{1}$ \\ ${ }^{1}$ Department of Internal Medicine Ward, The First Affiliated Hospital of The College of Medicine, \\ Zhejiang University, Hangzhou, Zhejiang $310003 ;{ }^{2}$ Department of Respiratory Diseases, \\ Tongde Hospital of Zhejiang Province, Hangzhou, Zhejiang 310012, P.R. China
}

Received May 19, 2018; Accepted September 27, 2018

DOI: $10.3892 /$ or.2018.6759

\begin{abstract}
Lung cancer is the principal cause of cancer-associated mortality. Pectolinarigenin (Pec) reportedly has effective antitumor activity against certain cancer types. Phosphatase and tensin homolog (PTEN) is a well-known tumor suppressor and serves a vital role in cancer progression. However, the effect of Pec on non-small cell lung cancer (NSCLC) cell proliferation and metastasis, and the underlying mechanism, has not yet been elucidated. In the present study, it was demonstrated that Pec inhibited the proliferation of A549 and Calu-3 cells in doseand time-dependent manners. The apoptosis rate significantly increased with increasing doses of Pec. Apoptosis-associated protein expression was additionally altered by Pec exposure. Pec was able to suppress the metastasis of NSCLC cells; it upregulated the mRNA and protein expression levels of E-cadherin, and downregulated the mRNA and protein expression levels of vimentin. Additionally, Pec was able to activate PTEN and subsequently downregulate the PI3K/protein kinase B (AKT) signaling pathway. In summary, Pec was able to inhibit cell proliferation, promote apoptosis and suppress metastasis in NSCLC cells through the PTEN/PI3K/AKT signaling pathway, indicating that $\mathrm{Pec}$ is a potential agent for NSCLC therapy.
\end{abstract}

\section{Introduction}

Lung cancer is one of the principal causes of cancer-associated mortality, and contributes to the economic burden worldwide.

Correspondence to: Dr Huiyun Pan, Department of Internal Medicine Ward, The First Affiliated Hospital of The College of Medicine, 79 Qingchun Road, Zhejiang University, Hangzhou, Zhejiang 310003, P.R. China

E-mail: panhuiyun123@zju.edu.cn

Abbreviations: EMT, epithelial-mesenchymal transition; NSCLC, non-small cell lung cancer; Pec, pectolinarigenin; PTEN, phosphatase and tensin homolog

Key words: Pec, proliferation, apoptosis, metastasis, NSCLC, PTEN
In total, $\sim 85 \%$ of confirmed lung cancer cases are classified as non-small cell lung cancer (NSCLC) (1-3). Traditionally, clinical methods, including surgery, chemotherapy or a combination are the primary treatment approaches for lung cancer. Recently, molecular-targeted drugs (4), anti-angiogenic therapy (5) and cancer immunotherapy (6) have been widely applied in patients with lung cancer. Despite advances in early diagnosis and standard treatment, the overall 5-year survival rate for NSCLC is $<15 \%$ (7), and there is an urgent requirement for the development of novel therapeutic approaches for NSCLC.

Phosphatase and tensin homolog (PTEN), located on chromosome 10q23, is well known as a tumor suppressor, and has lipid and protein phosphatase activities. It is involved in various cellular processes and signal transduction pathways in a complex network system (8-10). Emerging evidence has demonstrated that PTEN serves an important role in tumorigenesis and tumor suppression in multiple tumor types, including thyroid cancer (11), osteosarcoma (12), gastric cancer (13) and myeloma (14). The function of PTEN may be regulated by genetic mutations, transcriptional regulation and post-translational modifications $(8,10)$. Loss of PTEN or a decrease in PTEN expression levels and activity has been associated with poorer overall survival among patients with NSCLC. Therefore, regulation of PTEN has emerged as a promising research topic for cancer therapy (15).

In recent years, natural agents have attracted increasing attention due to the richness of the resource, easy accessibility and cost effectiveness for clinical application. As previously demonstrated, treatment with Osthole and Morinda citrifolia edible leaf extract $(16,17)$, regulated PTEN expression, inducing cancer growth and metastasis. Pectolinarigenin (Pec; $\mathrm{C}_{17} \mathrm{H}_{14} \mathrm{O}_{6}$; molecular weight: 314.28 ; melting point: $204-205^{\circ} \mathrm{C}$; storage conditions: $4^{\circ} \mathrm{C}$ refrigerated, sealed and protected from light) is a flavonoid compound widely distributed in a number of medicinal plants, including Cirsium japonlcum, Eupatorium odoratum and Trollius chinensis. Under the appearance of a yellow crystal, it is soluble in dimethyl sulfoxide and hot methanol, and insoluble in petroleum ether, chlorine and other solvents. As documented in previous studies, Pec has demonstrated effective antitumor activities in vivo and in vitro. Cheng et al (18) observed that Pec may inhibit cell viability and migration of nasopharyngeal carcinoma cells, and induce 
mitochondrial-associated apoptosis through the accumulation of caspase-3 and caspase-9 in cells. Zhang et al (19) demonstrated that Pec was able to disturb signal transducer and activator of transcription 3 (STAT3) signaling and decrease STAT3 downstream proteins, including cyclin D1, B-cell lymphoma 2 (BCL-2) B-cell lymphoma extra-large (BCL-xL), Myeloid cell leukemia 1 (MCL-1), contributing to the suppression of cell proliferation and apoptosis in osteosarcoma cells. Additionally, Pec was able to inhibit cell migration and invasion, and preserved the epithelial-mesenchymal transition (EMT) phenotype. As uncontrolled cell proliferation and metastasis are considered hallmarks of malignant tumors, inhibition of associated signaling pathways is one important aspect of cancer treatment.

It has been demonstrated that Pec may inhibit growth and metastasis of nasopharyngeal carcinoma cells and osteosarcoma cells $(18,19)$; however, the effect of Pec on NSCLC and its underlying mechanisms have not been reported. In the present study, the potential effects of Pec on human NSCLCs cells were investigated to clarify the possible underlying mechanisms. As a result, it was revealed that Pec may significantly inhibit cell proliferation, migration, invasion, EMT, and induce apoptosis in vitro by promoting the expression of PTEN.

\section{Materials and methods}

Cell lines and reagents. Human NSCLC cell lines A549 and Calu-3 were purchased from the Shanghai Institute of Biochemistry and Cell Biology (Shanghai, China). The two cell lines were cultured in RPMI-1640 medium with $10 \%$ fetal bovine serum (FBS), $100 \mathrm{U} / \mathrm{ml}$ penicillin and $100 \mu \mathrm{g} / \mathrm{ml}$ streptomycin (all from Gibco; Thermo Fisher Scientific, Inc., Waltham, MA, USA) in a $5 \% \mathrm{CO}_{2}$ incubator at $37^{\circ} \mathrm{C}$. Pec reagent was purchased from Abmole Bioscience Inc. (Houston, TX, USA). Antibodies against Bax (cat. no. 2744), BCL-xL (cat. no. 2762), PTEN (cat. no. 9188), phospho-phosphoinositide 3-kinase (p-PI3K; cat. no. 4228), phospho-protein kinase B (p-AKT; cat. no. 4060), cellular tumor antigen p53 (p53; cat. no. 9282), Lamin B1 (cat. no. 13435) and GAPDH (cat. no. 5174) were purchased from Cell Signaling Technology, Inc. (Danvers, MA, USA). Fluorescence-tagged secondary antibodies, IRDye ${ }^{\circledR}$ 680RD goat anti-rabbit IgG (cat. no. 925-68071) and IRDye ${ }^{\circledR}$ 680RD goat anti-mouse IgG (cat. no. 925-68070) were acquired from LI-COR Biosciences, Inc. (Lincoln, NE, USA). PTEN inhibitor SF1670 (cat. no. ab141303) and AKT activator SC79 (cat. no. ab146428) were purchased from Abcam (Cambridge, UK). SF1670 and/or SC79 $(10 \mu \mathrm{M})$ were applied to the culture medium for $1 \mathrm{~h}$ at room temperature in the treated group. NE-PER ${ }^{\mathrm{TM}}$ Nuclear and Cytoplasmic Extraction reagents (cat. no. 78835) were purchased from Thermo Fisher Scientific, Inc. The primary and secondary antibodies were respectively diluted to $1: 1,000$ and 1:4,000 in 5\% BAS (Sigma-Aldrich; Merck KGaA, Darmstadt, Germany).

Cell viability assay. Cells were grown in a 96-well plate overnight at a density of $4 \times 10^{3}$ cells/well, and subsequently treated with different concentrations of Pec for 24, 48 and 72 h. Following incubation, $10 \mu 1$ Cell Counting Kit-8 (CCK-8) reagent (Dojindo Molecular Technologies, Inc., Kumamoto,
Japan) was added to each well for $1 \mathrm{~h}$. The optical density of each sample was measured spectrophotometrically at $450 \mathrm{~nm}$ with an automatic microplate analyzer (Bio-Rad Laboratories, Inc., Hercules, CA, USA).

Colony formation assay. Cells were seeded in a 6-well plate at 400 cells/well. After $24 \mathrm{~h}$, the cells were treated with Pec at various concentrations $(0,10$ and $25 \mu \mathrm{M})$ and incubated at $37^{\circ} \mathrm{C}$ with $5 \% \mathrm{CO}_{2}$. The cells were consistently cultured for 10 days and the culture medium was changed every two days. The cells were washed twice with PBS and subsequently fixed with $4 \%$ paraformaldehyde for $30 \mathrm{~min}$ at room temperature. A crystal violet stain was used to observe colony formation.

Cell apoptosis assay. A cell apoptosis assay was conducted by flow cytometry with a Fluorescein Isothiocyanate (FITC) Annexin V Apoptosis Detection kit (BD Biosciences, Franklin Lakes, NJ, USA), according to the manufacturer's protocol. After treatment with Pec for $48 \mathrm{~h}$, the cells were harvested and resuspended in binding buffer at a concentration of $1 \times 10^{6}$ cells/ml. Subsequently, $5 \mu \mathrm{l}$ FITC Annexin V and $5 \mu \mathrm{l}$ Propidium Iodide Staining Solution were added to a $200-\mu 1$ cell suspension, and incubated for $30 \mathrm{~min}$ at room temperature in the dark. Cell apoptosis was detected using BD FACSVerse (BD Biosciences) and the apoptosis rate of cancer cells was analyzed using FlowJo software version 7.0 (FlowJo LLC, Ashland, OR, USA).

Western blot analysis. Cells were harvested and washed twice with PBS, subsequently lysed with radioimmunoprecipitation buffer and $1 \mathrm{X}$ protease inhibitors $(100: 1)$ at $4^{\circ} \mathrm{C}$ for $30 \mathrm{~min}$. Subsequent to centrifuging at $12,000 \mathrm{x}$ g for $10 \mathrm{~min}$ at $4^{\circ} \mathrm{C}$, the supernatant was collected and the protein concentration in the supernatant fractions was quantified using a Bicinchoninic Acid Protein Assay kit (Thermo Fisher Scientific, Inc.). The remaining supernatant was mixed with SDS-PAGE loading buffer and boiled at $100^{\circ} \mathrm{C}$ for $10 \mathrm{~min}$. The same amount of protein (20 $\mu \mathrm{g}$ ) was separated using 12\% SDS-PAGE and subsequently transferred to polyvinylidene difluoride membranes (EMD Millipore, Billerica, MA, USA). Blocking buffer was used to block the non-specific binding sites in the membranes for $15 \mathrm{~min}$ at room temperature. Primary antibodies were incubated with the membranes overnight at $4^{\circ} \mathrm{C}$. The membranes were washed three times with PBS and incubated with fluorescence-tagged secondary antibodies for $1 \mathrm{~h}$. Images of the membranes were captured with the Odyssey CLx Infrared Imaging System (LI-COR Biosciences, Lincoln, NE, USA). GAPDH and Lamin $\mathrm{B} 1$ protein intensity was used as internal controls for cytoplasm and nucleus fractions, respectively.

Reverse transcription-quantitative polymerase chain reaction $(R T-q P C R)$. Total RNA of the NSCLC cells treated with or without Pec were collected and extracted with RNeasy Mini RNA kit (Qiagen GmbH, Hilden, Germany) according to the manufacturer's protocol. The concentrations of total RNA were detected with NanoDrop 2000 and reversed transcribed into cDNA (Takara Biotechnology Co., Ltd., Dalian, China). The SYBR kit (Qiagen $\mathrm{GmbH}$ ) was used for the detection of E-cadherin, vimentin and GAPDH. The primers sequences were as follows: E-cadherin forward, 5'-CGAGAGCTACAC 

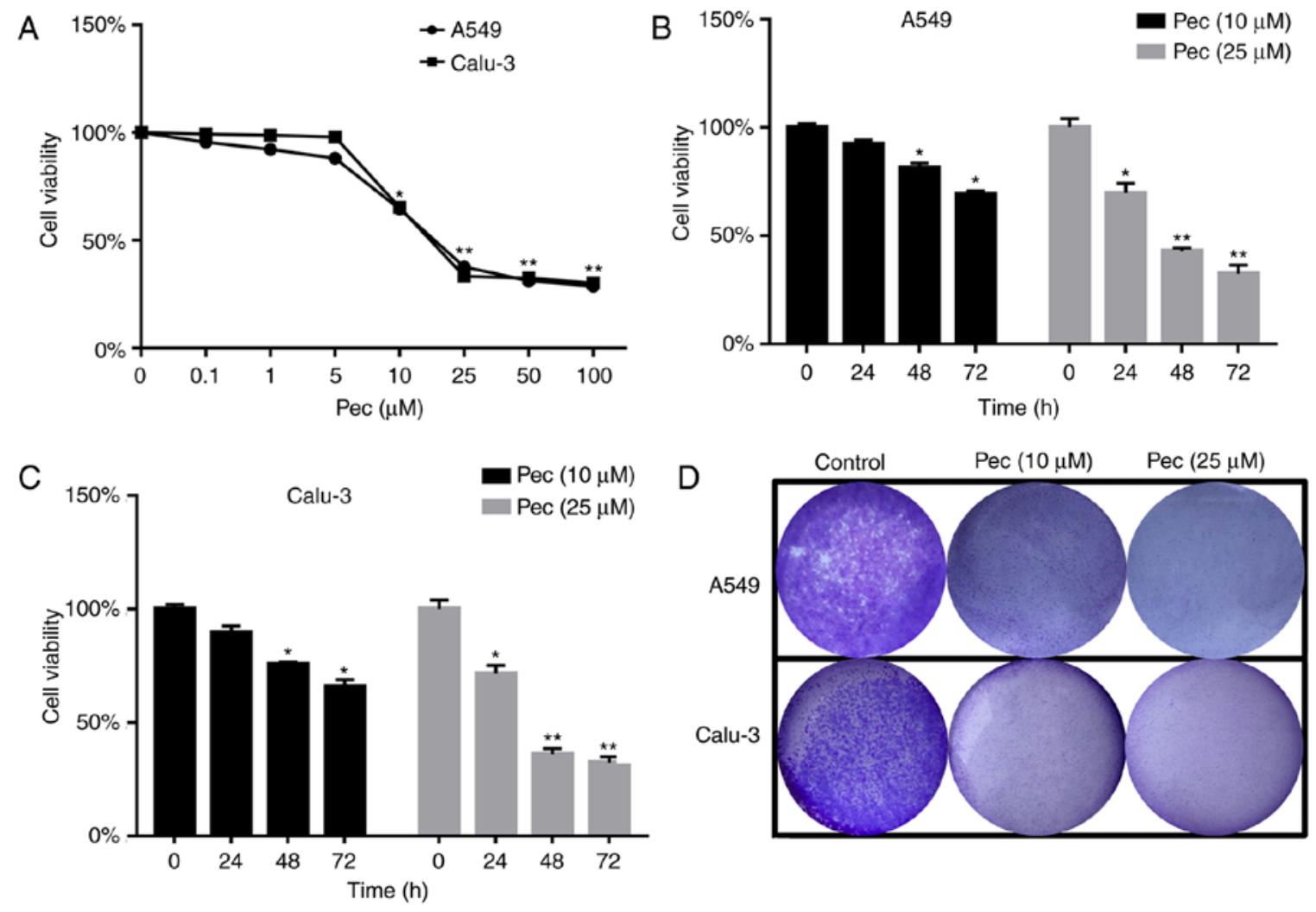

Figure 1. Pec inhibits proliferation in lung adenocarcinoma cells. (A) A549 and Calu-3 cells were incubated with Pec at different concentrations ( $0,0.1,1,5,10$, 25,50 and $100 \mu \mathrm{M}$ ) for $72 \mathrm{~h}$. (B and C) A549 and Calu-3 cells were exposed to Pec (10 and $25 \mu \mathrm{M}$ ) for different time-points (24, 48 and $72 \mathrm{~h}$ ). Cell viability and $\mathrm{IC}_{50}$ values were measured using Cell Counting Kit-8 assays. (D) Clonogenic survival assay of A549 and Calu-3 cells treated with Pec (10 and $25 \mu \mathrm{M}$ ). Each experiment was performed three times. The data are presented as the mean \pm standard deviation. ${ }^{*} \mathrm{P}<0.05,{ }^{* *} \mathrm{P}<0.01$. Pec, pectolinarigenin; $\mathrm{IC}_{50}$, half maximal inhibitory concentration.

GTTCACGG-3' and reverse, 5'-GGGTGTCGAGGGAAA AATAGG-3'; vimentin forward, 5'-GACGCCATCAACACC GAGTT-3' and reverse, 5'-CTTTGTCGTTGGTTAGCT GGT-3'; GAPDH forward, 5'-GGAGCGAGATCCCTCCAA AAT-3' and reverse, 5'-GGCTGTTGTCATACTTCTCAT GG-3'. The densitometry of relative mRNA expression was performed using the calculation of $2^{-\triangle \Delta C q}(20)$ and GAPDH was used as an internal control.

Wound scratch assay. Cancer cell migration was assessed using a cell wound scratch assay. NSCLC cells were seeded in a 6-well plate and incubated overnight to form a confluent cell monolayer, and a scratch was made with a $100-\mu 1$ sterile pipette tip. The cancer cells were subsequently treated with or without Pec for $24 \mathrm{~h}$ and images of the scratches were obtained with an inverted microscope (Olympus Corp., Tokyo, Japan).

Transwell assay. For the invasion assay, the upper chambers were pre-coated with Matrigel (Invitrogen; Thermo Fisher Scientific, Inc.), the NSCLC cancer cells $\left(1 \times 10^{5}\right.$ cells/well $)$ were plated on the upper chamber with Pec $(25 \mu \mathrm{M})$ or alone; whereas, the lower chamber contained RPMI-1640 medium with $10 \%$ FBS and $1 \%$ penicillin/streptomycin. After $24 \mathrm{~h}$ of incubation, the upper chambers were swabbed out, and the lower chambers were fixed with paraformaldehyde and stained with crystal violet. Images of the invaded cells were captured with a Leica fluorescence microscope (magnification, x100; Olympus Corp.).
Statistical analysis. All data were analyzed using SPSS 19.0 software (IBM Corp., Armonk, NY, USA) and comparisons between groups were determined by Student's t-test. The results are presented as the mean \pm standard deviation. $\mathrm{P}<0.05$ was considered to indicate a statistically significant difference. All experiments were repeated at least three times independently.

\section{Results}

Pec inhibits cell proliferation in A549 and Calu-3 cells. It was reported that Pec exhibited an inhibitory effect on nasopharynx carcinoma (18); thus, in order to investigate whether Pec had a similar effect on NSCLC cells, a cell proliferation assay was conducted using a CCK- 8 assay. The results revealed that the cell viability of A549 and Calu-3 cells was decreased following administration of Pec. The CCK-8 assay demonstrated that Pec was able to significantly inhibit the cell proliferation in dose- (Fig. 1A) and time-dependent (Fig. 1B and C) manners, with half maximal inhibitory concentration values of 21.49 and $22.63 \mu \mathrm{M}$, respectively. In addition, the colony formation assay demonstrated that the growth rate was markedly decreased in the two cell lines treated with Pec (Fig. 1D). These results indicated that Pec exhibited an inhibitory effect on the proliferation of NSCLC cells.

Pec induces the apoptosis of human NSCLC cells. To determine the effect of Pec on NSCLC cell apoptosis, flow 

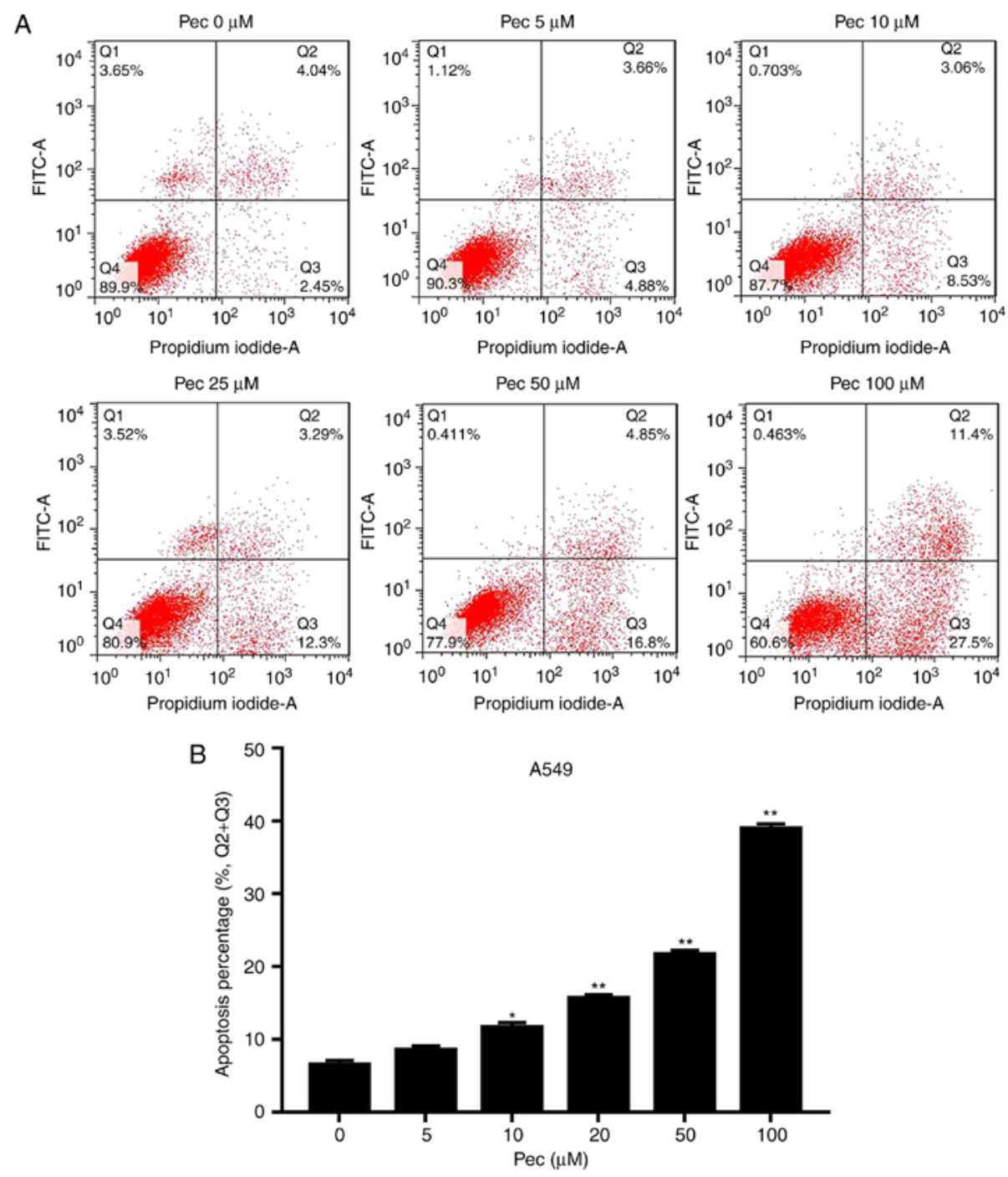

Figure 2. Pec induces apoptosis in lung adenocarcinoma cells. (A and B) A549 cells were treated with Pec at different concentrations $(0,5,10,25,50$ and $100 \mu \mathrm{M})$ for $48 \mathrm{~h}$. Flow cytometric analysis demonstrated that Pec induced increased apoptosis with increased doses of Pec. Each experiment was performed three times. The data are presented as the mean \pm standard deviation. ${ }^{*} \mathrm{P}<0.05,{ }^{* *} \mathrm{P}<0.01$. Pec, pectolinarigenin.

cytometry was conducted to detect the apoptosis of cells treated with Pec. As presented in Fig. 2, the apoptosis rate of the A549 and Calu-3 cell lines increased gradually with the administration of different concentrations of Pec $(0,5,10,25$, 50 and $100 \mu \mathrm{M}$ ) for $48 \mathrm{~h}$, particularly the A549 cell line.

Furthermore, western blot analysis demonstrated that the pro-apoptotic Bax protein expression level was upregulated; whereas, the anti-apoptotic BCL-xL protein expression level was downregulated in the A549 cell line (Fig. 3A), and similar results were additionally observed in the Calu-3 cell line (Fig. 3B). Therefore, it was hypothesized that Pec exhibited an antitumor effect by inducing NSCLC cancer cell apoptosis and apoptosis-associated protein expression levels.

Pec decreases the migration, invasion and EMT of NSCLC cells. To examine whether Pec was able to inhibit the migration, invasion and EMT of NSCLC cells, a cell wound scratch assay was performed and the two cell lines were treated without or with Pec $(25 \mu \mathrm{M})$. After $24 \mathrm{~h}$ of incubation, Pec significantly inhibited the migration of NSCLC cells compared with the control groups (Fig. 4A). A Transwell assay was conducted to detect the invasion of NSCLC cells; the results demonstrated that Pec suppressed the invasion of A549 and Calu-3 cells (Fig. 4B). Furthermore, the expression of epithelial marker E-cadherin and mesenchymal marker vimentin was detected by RT-qPCR and western blotting. The EMT process is considered the initial step for cancer metastasis; Pec markedly upregulated the expression of E-cadherin and downregulated the vimentin expression at the mRNA (Fig. 4C) and protein expression levels (Fig. 4D). Collectively, treatment with Pec suppressed the metastasis and EMT of NSCLC cells.

Effects of Pec on the PTEN/PI3K/AKT pathway in A549 and Calu-3 cells. A previous study suggested that the PTEN/PI3K/AKT pathway is involved in cancer progression (21-25), thus, the effect of Pec on the PTEN/PI3K/AKT pathway in A549 and Calu-3 cells was evaluated by western blotting to examine the underlying mechanism of Pec-mediated inhibition of cell proliferation and metastasis. In the present study, the results of western blotting demonstrated that the expression of phospho-PI3K and phospho-AKT was significantly decreased; whereas, the PTEN protein expression 

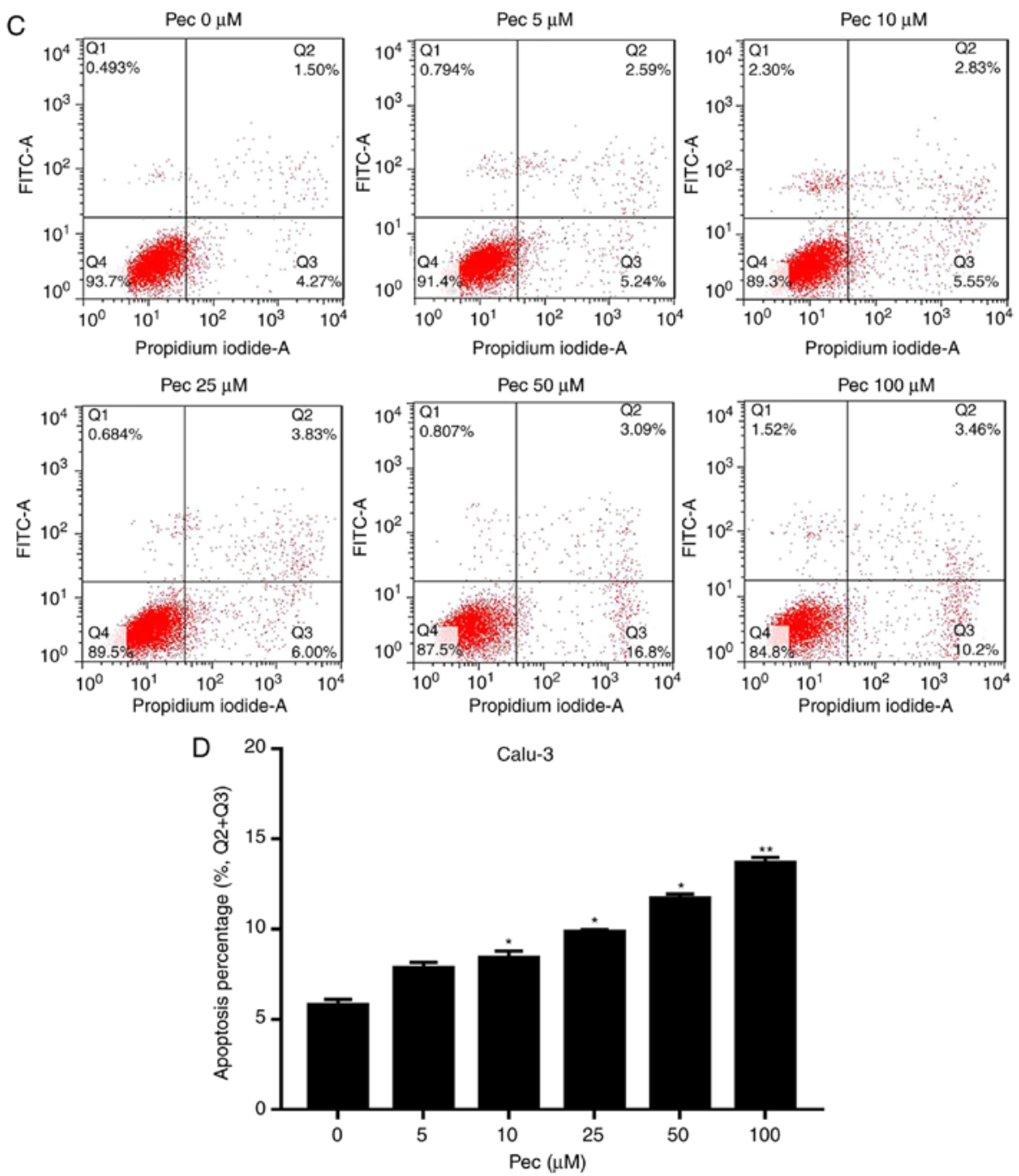

Figure 2. Continued. Pec induces apoptosis in lung adenocarcinoma cells. (C and D) Calu-3 cells were treated with Pec at different concentrations $(0,5,10,25,50$ and $100 \mu \mathrm{M})$ for $48 \mathrm{~h}$. Flow cytometric analysis demonstrated that Pec induced increased apoptosis with increased doses of Pec. Each experiment was performed three times. The data are presented as the mean \pm standard deviation. ${ }^{~} \mathrm{P}<0.05,{ }^{* *} \mathrm{P}<0.01$. Pec, pectolinarigenin.

A

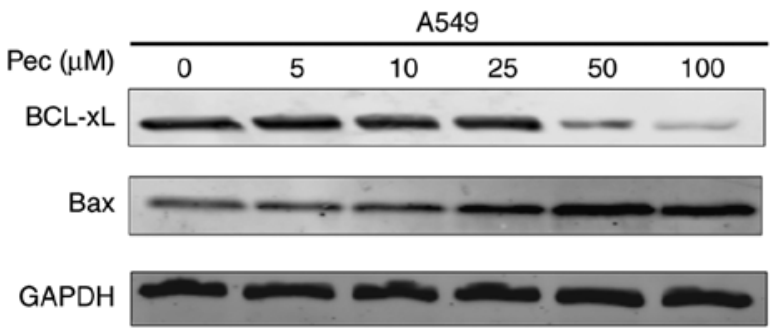

B

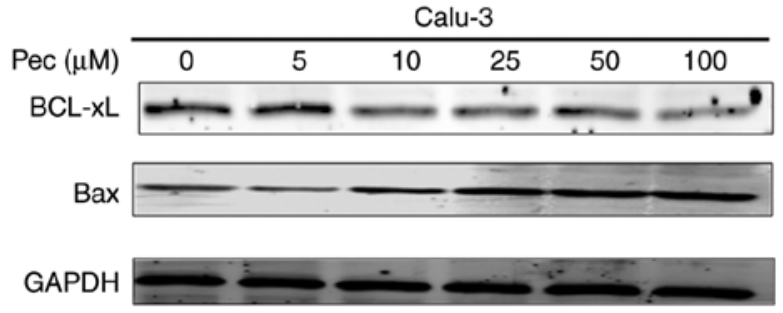

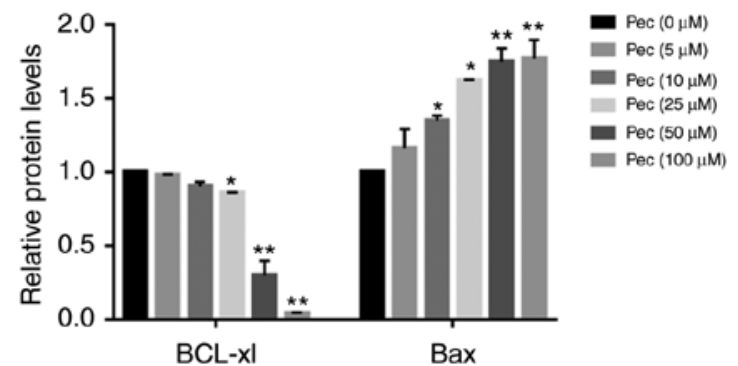

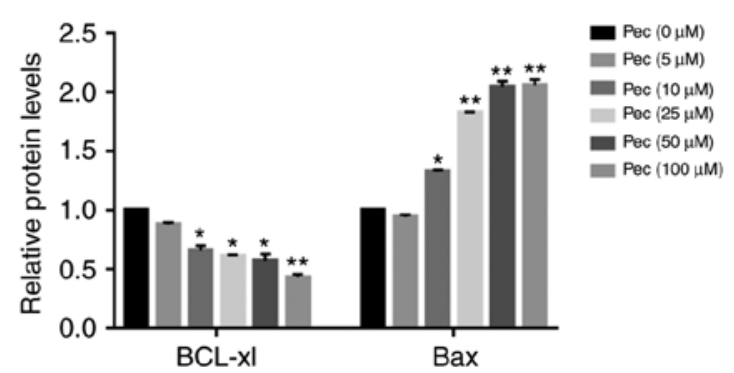

Figure 3. Pec-mediated expression of apoptosis-associated proteins is altered. (A and B) Western blot analysis demonstrated that Pec downregulated the expression of anti-apoptosis protein BCL-xL and upregulated pro-apoptosis protein Bax with increasing concentrations in A549 and Calu-3 cells. Each experiment was performed three times. The data are presented as the mean \pm standard deviation. ${ }^{*} \mathrm{P}<0.05,{ }^{* *} \mathrm{P}<0.01$. Pec, pectolinarigenin; BCL-xL, B-cell lymphoma-extra large; Bax, apoptosis regulator BAX. 
A
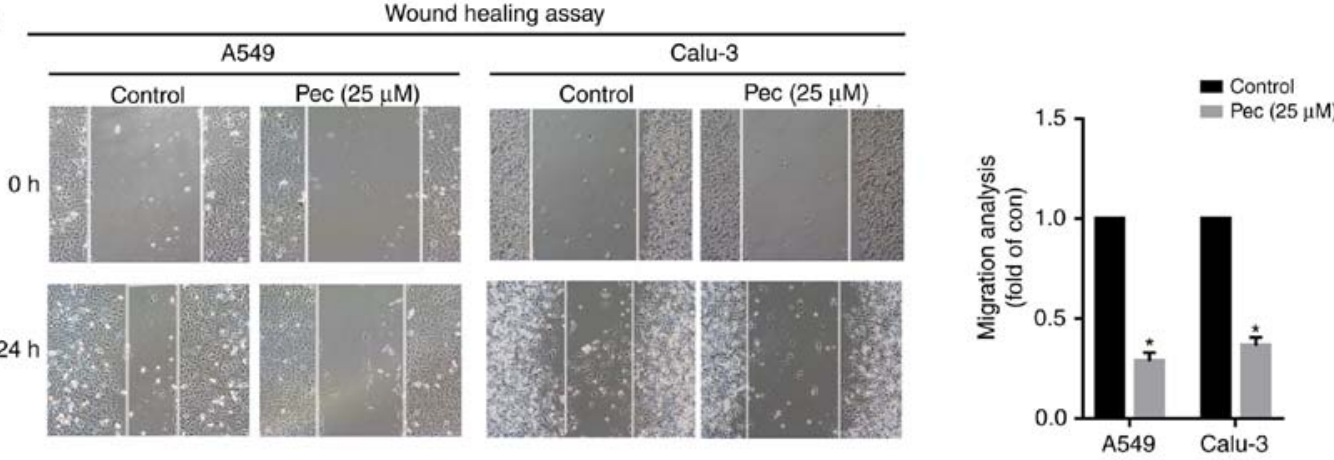

B
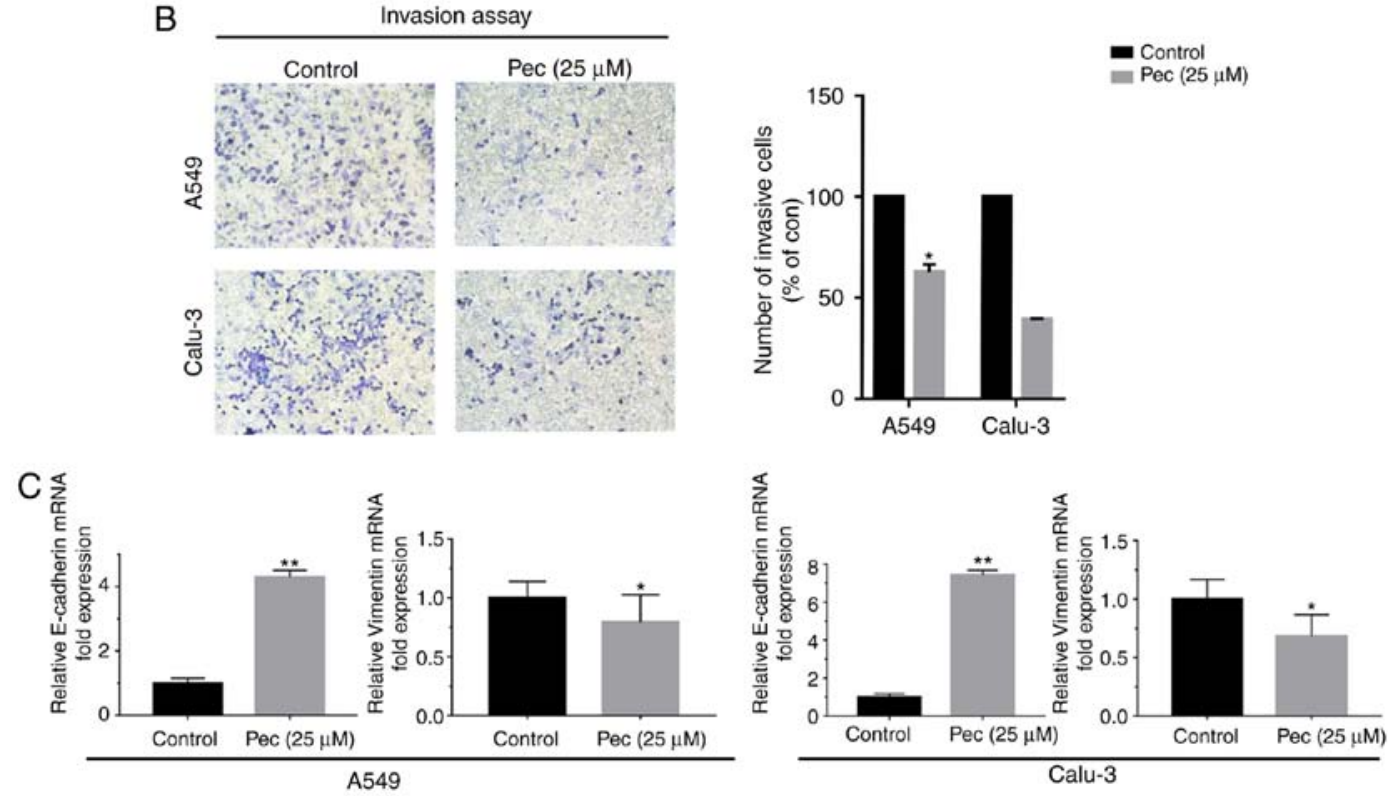

D A549
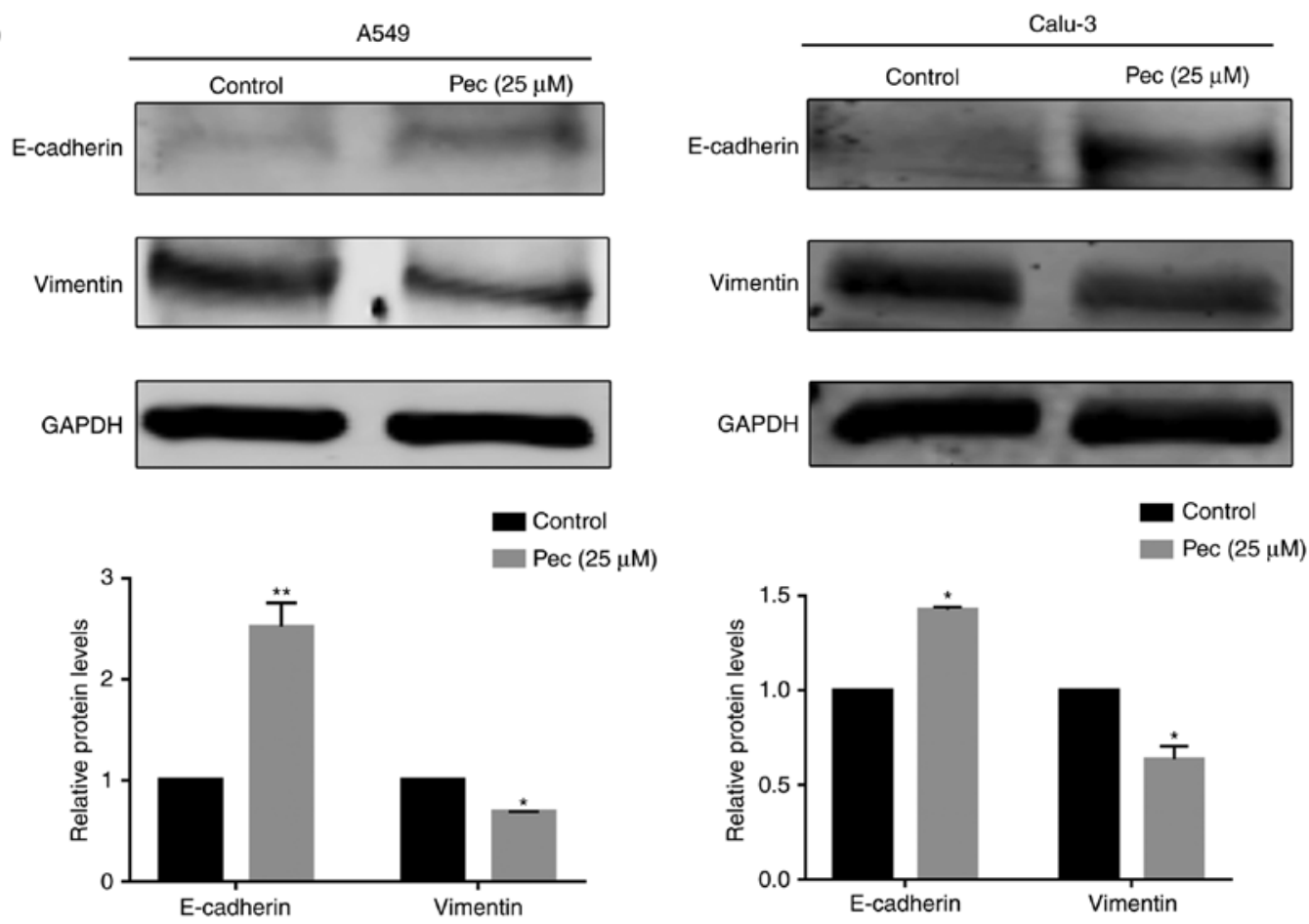

Figure 4. Pec inhibits the migration, invasion and EMT of NSCLC cells. (A) A cell wound scratch assay was performed to assess NSCLC cell migration; cells were treated without or with Pec $(25 \mu \mathrm{M})$ for $24 \mathrm{~h}$. (B) Transwell invasion assays were performed for NSCLC (A549, upper images; Calu-3, lower images) cells. (C) Quantitative analysis of E-cadherin and vimentin mRNA expression. NSCLC cells were not treated or treated with Pec ( $25 \mu \mathrm{M})$ and RNA was subjected to reverse transcription-quantitative polymerase chain reaction. (D) NSCLC A549 and Calu-3 cells were treated without or with Pec ( $25 \mu \mathrm{M})$, and the cellular extract was subjected to western blotting for analysis of E-cadherin and vimentin protein expression. Each experiment was performed three times. The data are presented as the mean \pm standard deviation. ${ }^{*} \mathrm{P}<0.05,{ }^{* *} \mathrm{P}<0.01$. Pec, pectolinarigenin; EMT, epithelial-mesenchymal transition; NSCLC, non-small cell lung cancer. 
A

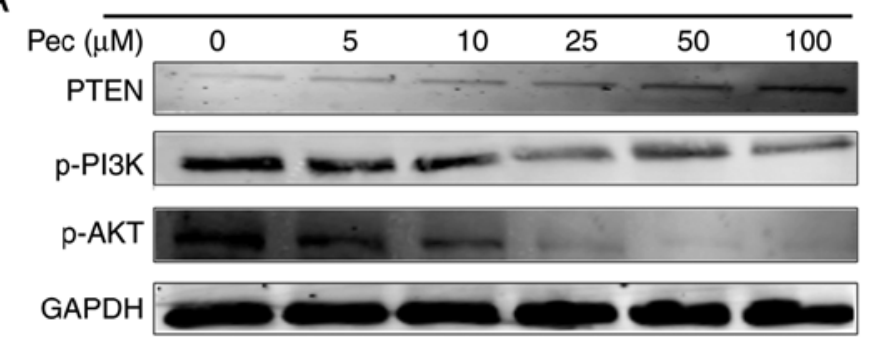

B

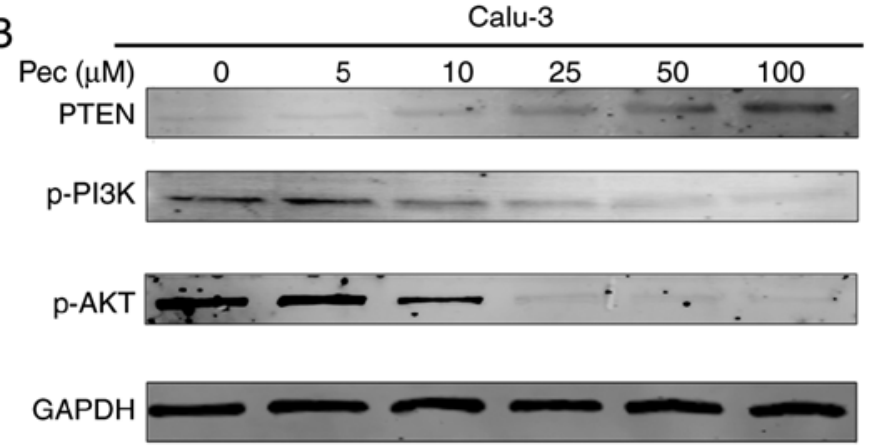

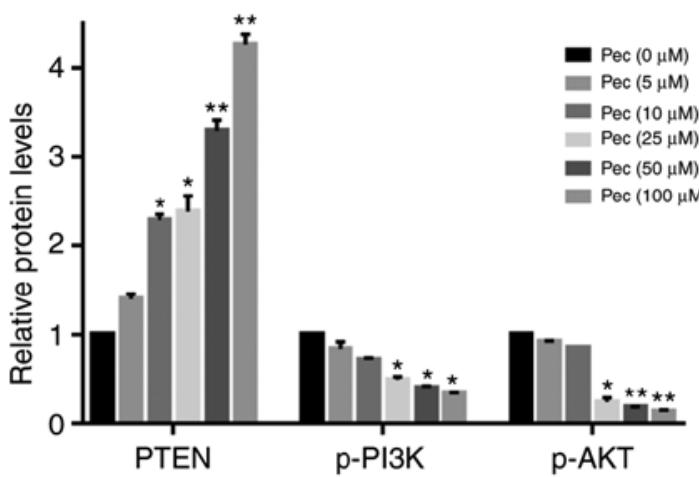

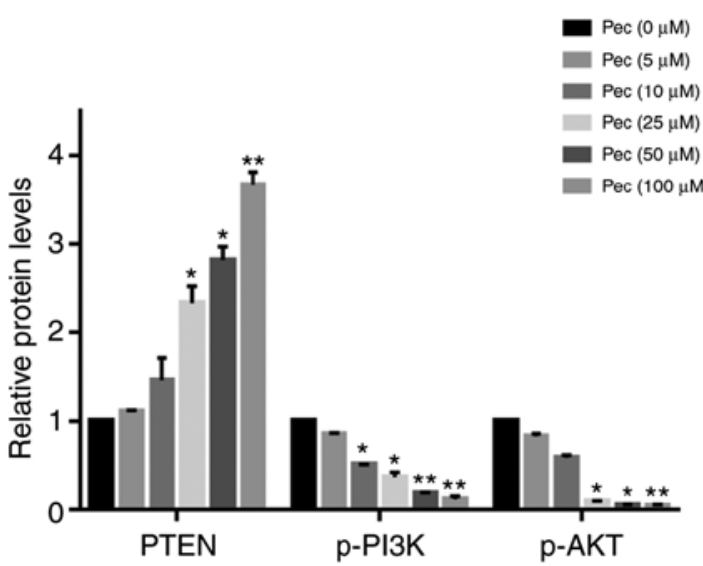

Figure 5. Pec induces apoptosis through the PTEN/PI3K/AKT signaling pathway. (A and B) Western blot analysis demonstrated that Pec activated PTEN and downregulated the PI3K/AKT signaling pathway in A549 and Calu-3 cells. Each experiment was performed three times. The data are presented as the mean \pm standard deviation. ${ }^{*} \mathrm{P}<0.05,{ }^{* *} \mathrm{P}<0.01$. Pec, pectolinarigenin; PTEN, phosphatase and tensin homolog; PI3K, phosphoinositide 3 -kinase; AKT, protein kinase B.

level was increased with increasing concentrations of Pec (Fig. 5). Previous studies suggested a complicated association and interaction between PTEN and p53 $(26,27)$. To confirm whether $\mathrm{p} 53$ is involved in the pathway mediated by PTEN, cells were pre-treated with Pec and/or an inhibitor of PTEN (SF1670), and the protein expression level of PTEN and p53 was detected. The present results indicated that the altered expression of PTEN was associated with p53 expression. Treatment with SF1670 alone inhibited PTEN and p53 expression; whereas, combined treatment of Pec and SF1670 in NSCLC cells abolished the SF1670-induced effect on PTEN and p53 (Fig. 6A). Furthermore, activation of AKT by SC79, a novel AKT activator, decreased the expression of $\mathrm{p} 53$, which indicated that $\mathrm{p} 53$ was negatively regulated by PTEN/PI3K/AKT (Fig 6B). Generally, the present results revealed that Pec exerted antitumor activity through the PTEN/PI3K/AKT signaling pathway and p53 served an important role in the signaling pathway mediated by PTEN. The specific schematic diagram of PTEN/PI3K/AKT and the crosstalk between p53 and PTEN is presented in Fig. 7. Additionally, it was identified that Pec was able to promote the translocation of PTEN from the cytoplasm to the nucleus to exert antitumor activity (data not shown), which is consistent with previous studies (28).

\section{Discussion}

Lung cancer, particularly NSCLC, is responsible for the majority of cancer-associated mortalities; there were
1.69 million mortalities of patients with lung cancer reported in 2015 worldwide $(3,7)$. Although the development of novel therapies has greatly ameliorated the conditions of patients with lung cancer, the 5-year survival rate has not improved much primarily due to resistance to antitumor agents and toxic side-effects (29). In clinical treatments, drug resistance remains one of the principal issues in developing a successful treatment for cancer. It is important to develop more effective drugs against lung cancer with fewer side-effects.

In recent years, there have been an increasing number of previous studies investigating the antitumor activity of medicinal plant extracts, which have successfully demonstrated their potential use in treatments. Previous modern pharmacological studies demonstrated the excellent antitumor effects of various medicinal plant extracts, including oxymatrine (30) and deguelin (31). Pec is a natural extract from a diverse range of herbal medicine and was previously demonstrated to have an antitumor effect on nasopharyngeal carcinoma (18) and osteosarcoma (19). However, there has been no study, to the best of our knowledge, on the biological activity of Pec in human NSCLC cells. With regard to the identification of the anticancer effects of Pec on NSCLC cells, in the present study, experiments were conducted to demonstrate the inhibitory effect of Pec on NSCLC cell proliferation and metastasis.

In the present study, it was observed that Pec was able to significantly decrease the cell viabilities of A549 and Calu-3 cancer cells in dose- and time-dependent manners with the administration of Pec. Pec-mediated cell apoptosis was 
A

p53
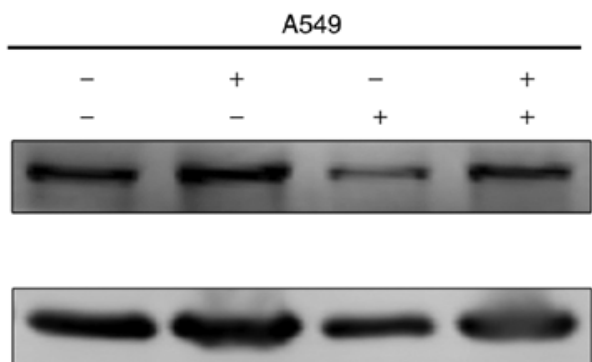

GAPDH
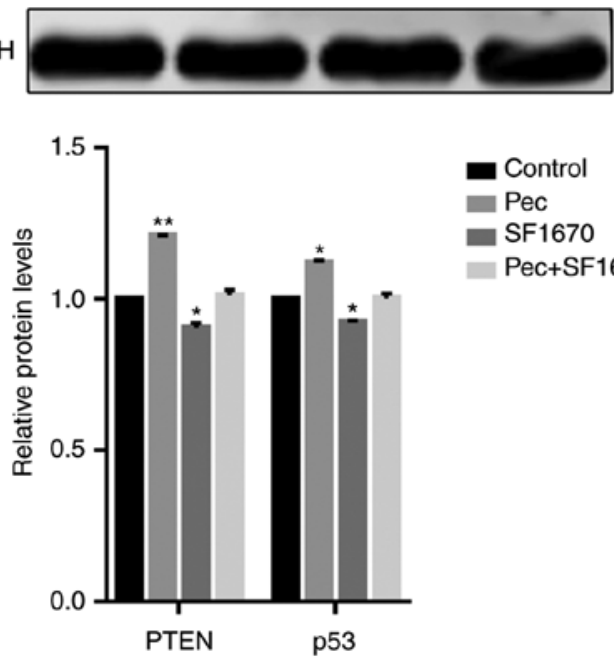

B

p53

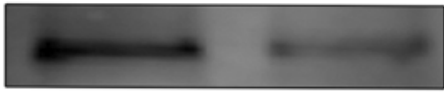

GAPDH
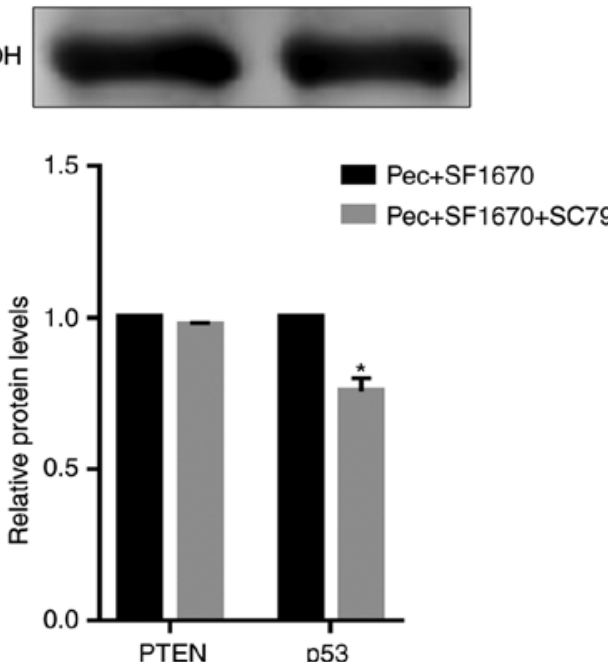

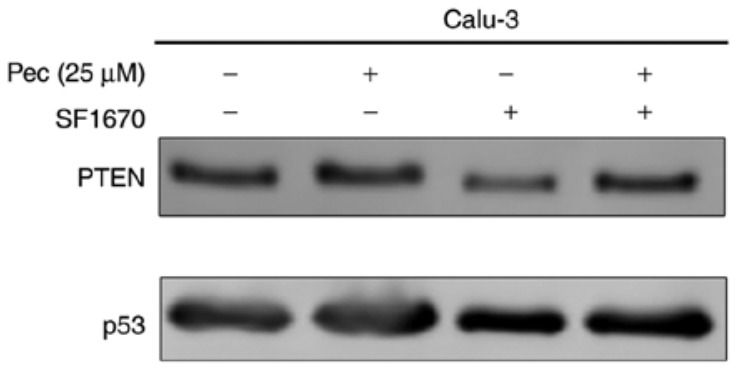

GAPDH
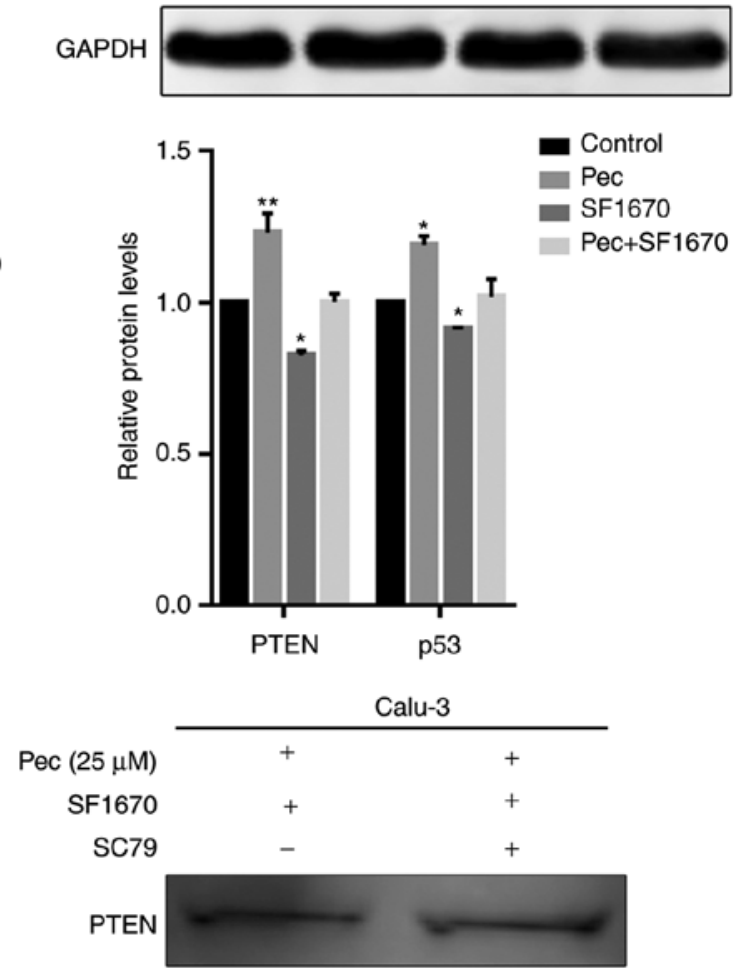

p53
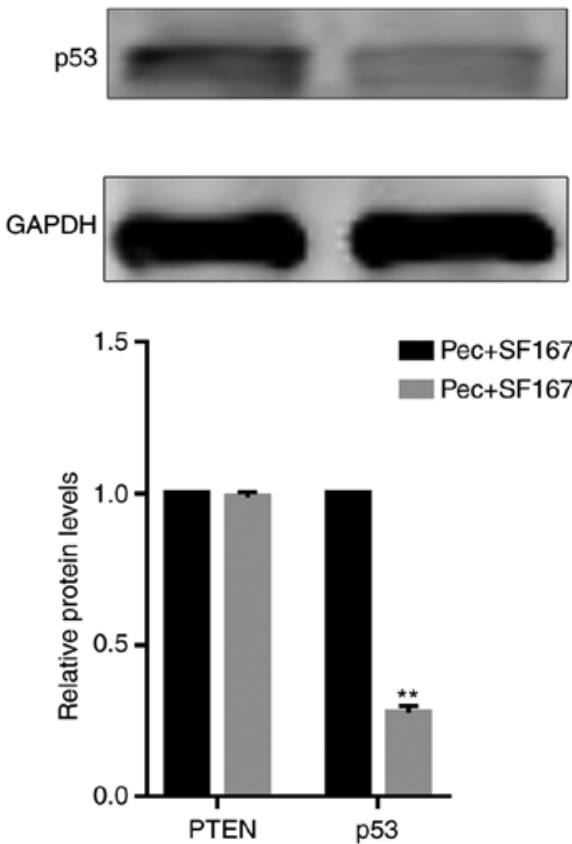

Figure 6. p53 is involved in the PTEN-mediated PI3K/AKT signaling pathway. (A) A549 and Calu-3 cells were treated with Pec (25 $\mu \mathrm{M}$; 24 h) and/or PTEN inhibitor (SF1670; $10 \mu \mathrm{M} ; 1 \mathrm{~h}$ ). Expression of the indicated proteins was detected by western blotting and subsequent statistical analysis was performed. (B) Following activation of AKT with SC79 $(10 \mu \mathrm{M} ; 1 \mathrm{~h})$, PTEN and p53 protein expression levels were additionally quantified by western blot analysis. Each experiment was performed three times. The data are presented as the mean \pm standard deviation. ${ }^{*} \mathrm{P}<0.05,{ }^{* *} \mathrm{P}<0.01$. p53, cellular tumor antigen p53; PTEN, phosphatase and tensin homolog; PI3K, phosphoinositide 3-kinase; PKT, protein kinase B; Pec, pectolinarigenin. 


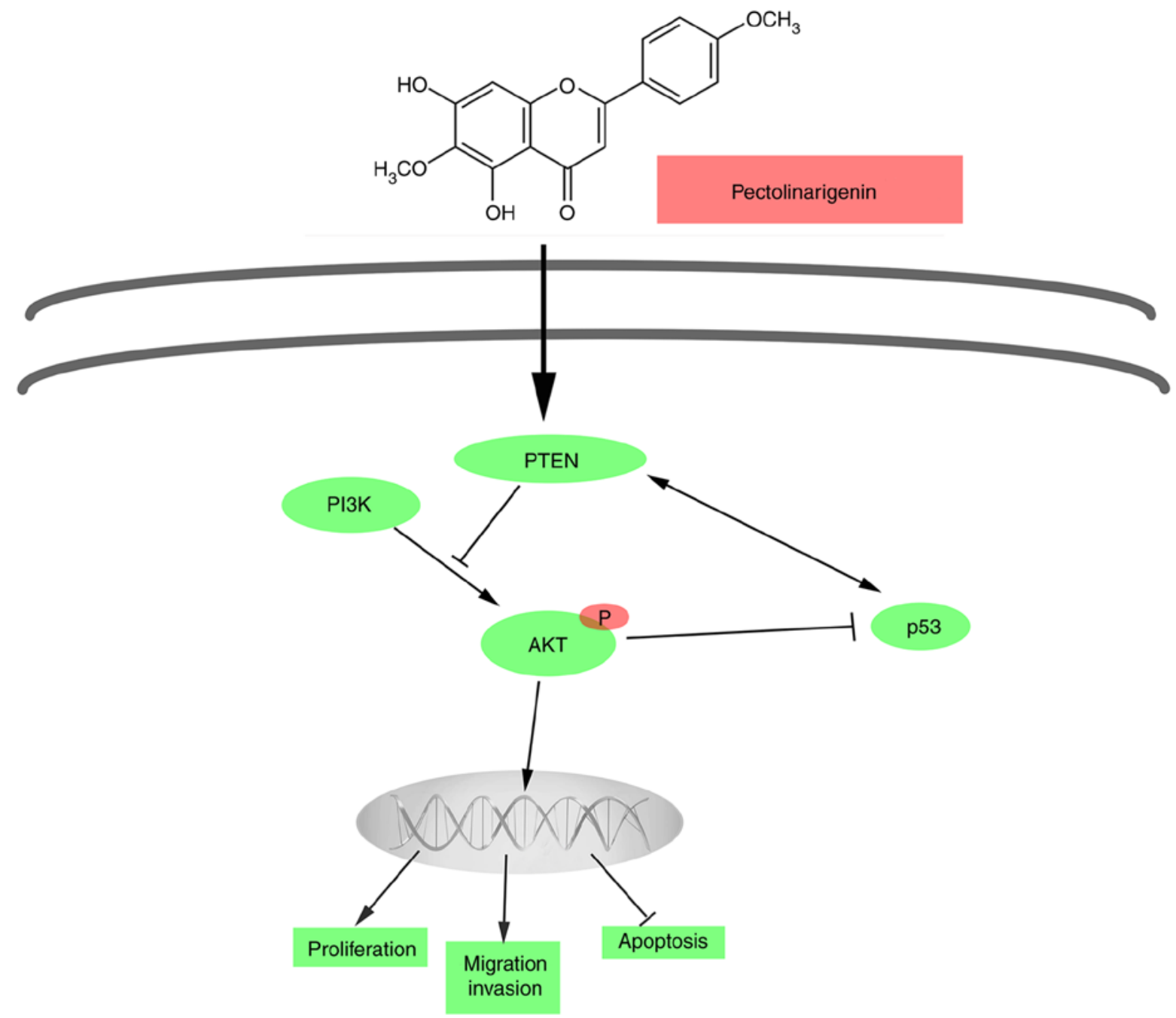

Figure 7. Schematic diagram of Pec-induced proliferation, apoptosis, migration and invasion in NSCLC cells through the PTEN/PI3K/AKT pathway. Specific critical pathways have been omitted for clarity. Pec, pectolinarigenin; NSCLC, non-small cell lung cancer; PTEN, phosphatase and tensin homolog; PI3K, phosphoinositide 3-kinase; AKT, protein kinase B.

augmented with increasing Pec concentrations, demonstrating a dose-dependent effect. Furthermore, it was observed that Pec significantly inhibited the migration and invasion of cancer cells, and upregulated E-cadherin expression; whereas it downregulated vimentin expression. Collectively, these results indicated that Pec exerted an effective anticancer activity against lung cancer.

Furthermore, an aim of the present study was to elucidate the underlying mechanisms involved in Pec-induced antitumor progression. It was previously observed that PTEN, a tumor suppressor phosphatase, may negatively regulate the activation of the PI3K/AKT signaling pathway (22). The PI3K/AKT pathway is essential for maintaining cell growth, survival, death and metabolism, and is commonly activated in cancer initiation and progression (32). Activation of the PTEN/PI3K/AKT pathway may be a therapeutic molecular target for lung cancer. (26). In the past decade, it was demonstrated that various natural compounds positively regulated PTEN gene expression, consequently exerting an inhibitory effect against tumors. Similarly, in the present study, it was demonstrated that Pec activated PTEN and downregulated the activity of PI3K/AKT, which indicated that the PTEN/PI3K/AKT signaling pathway was involved in the Pec-induced antitumor effect. It was additionally revealed that Pec was able to promote the nuclear translocation of PTEN. Furthermore, p53 is a well-documented tumor suppressor protein and is involved in apoptosis, autophagy, cell cycle regulation, and DNA replication and repair. Previous studies have indicated that PTEN could regulate 553 protein stability by antagonizing the PI3K/AKT-mediated MDM2 (murine double minute 2)-p53 pathway or by interacting with $\mathrm{p} 53$ directly. The present results indicated that p53, as a complementary signal, was involved in the PTEN-mediated PI3K/AKT pathway. However, cancer cell growth and metastasis is a complicated process in which multiple signaling pathways are involved (33-35). Therefore, whether other signaling pathways are involved in the Pec-induced anticancer effect and the PTEN-mediated p53 signaling pathway through a phosphatase-dependent manner or phosphatase-independent manner requires further investigation.

In conclusion, the present study demonstrated that Pec exhibited an antitumor effect on human NSCLC cancer cell lines, which was able to inhibit NSCLC cell proliferation, metastasis and EMT, and promote apoptosis through the 
PTEN/PI3K/AKT signaling pathway. Pec has potential for further development and may provide additional strategies for mono-therapy or combination treatments for NSCLC.

\section{Acknowledgements}

The authors thank Mr. D. Zhao for the technical support.

\section{Funding}

The present study was supported by grants from the Public Welfare Project of Zhejiang Province (grant no. 2012C23074) and the Natural Science Found of Zhejiang Province (grant no. Y2110167).

\section{Availability of data and materials}

The datasets used during the current study are available from the corresponding author upon reasonable request.

\section{Authors' contributions}

FX and HP designed and conceived the study. FX and XG performed the experiments, analyzed the data and wrote the manuscript. HP reviewed and edited the manuscript, as well as provided funds. All authors read and approved the manuscript and agree to be accountable for all aspects of the research in ensuring that the accuracy or integrity of any part of the work are appropriately investigated and resolved.

\section{Ethics approval and consent to participate}

Not applicable.

\section{Patient consent for publication}

Not applicable.

\section{Competing interests}

The authors declare that they have no competing interests.

\section{References}

1. Smith RA, Andrews KS, Brooks D, Fedewa SA, Manassaram-Baptiste D, Saslow D, Brawley OW and Wender RC: Cancer screening in the United States, 2017: A review of current american cancer society guidelines and current issues in cancer screening. CA Cancer J Clin 67: 100-121, 2017.

2. By the numbers: Cancer mortality, 2011-2015. Cancer Discov 8: 907, 2018.

3. de Groot PM, Wu CC, Carter BW and Munden RF: The epidemiology of lung cancer. Transl Lung Cancer Res 7: 220-233, 2018.

4. Rybarczyk-Kasiuchnicz A and Ramlau R: Current views on molecularly targeted therapy for lung cancer-a review of literature from the last five years. Kardiochir Torakochirurgia Pol 15: 119-124, 2018.

5. Varol M, Koparal AT, Benkli K and Bostancioglu RB: Anti-lung cancer and anti-angiogenic activities of new designed boronated phenylalanine metal complexes. Curr Drug Deliv: Jul 27, 2018 (Epub ahead of print).

6. Miura Y and Sunaga N: Role of immunotherapy for oncogene-driven non-small cell lung cancer. Cancers (Basel) 10: E245, 2018.
7. Chen W, Zheng R, Baade PD, Zhang S, Zeng H, Bray F, Jemal A, Yu XQ and He J: Cancer statistics in China, 2015. CA Cancer J Clin 66: 115-132, 2016.

8. Chen CY, Chen J, He L and Stiles BL: PTEN: Tumor suppressor and metabolic regulator. Front Endocrinol (Lausanne) 9: 338, 2010.

9. Jamaspishvili T, Berman DM, Ross AE, Scher HI, De Marzo AM, Squire JA and Lotan TL: Clinical implications of PTEN loss in prostate cancer. Nat Rev Urol 15: 222-234, 2018.

10. Lee YR, Chen M and Pandolfi PP: The functions and regulation of the PTEN tumour suppressor: New modes and prospects. Nat Rev Mol Cell Biol 19: 547-562, 2018.

11. Kong Y, Yin J, Fu Y, Chen Y, Zhou Y and Geng X: Suppression of Elk1 inhibits thyroid cancer progression by mediating PTEN expression. Oncol Rep 40: 1769-1776, 2018.

12. Tian DD, Zhang RX, Wu N, Yuan W, Luo SH, Chen HQ, Liu Y, Wang Y, He BC and Deng ZL: Tetrandrine inhibits the proliferation of human osteosarcoma cells by upregulating the PTEN pathway. Oncol Rep 37: 2795-2802, 2017.

13. Xiong J, Li Z, Zhang Y, Li D, Zhang G, Luo X, Jie Z, Liu Y, Cao Y, Le Z, et al: PRL-3 promotes the peritoneal metastasis of gastric cancer through the PI3K/Akt signaling pathway by regulating PTEN. Oncol Rep 36: 1819-1828, 2016.

14. Zhang J, Yang $\mathrm{C}$, Zhou $\mathrm{F}$ and Chen X: PDK1 inhibitor GSK2334470 synergizes with proteasome inhibitor MG132 in multiple myeloma cells by inhibiting full AKT activity and increasing nuclear accumulation of the PTEN protein. Oncol Rep 39: 2951-2959, 2018.

15. Zhao Y, Zheng R, Li J, Lin F and Liu L: Loss of phosphatase and tensin homolog expression correlates with clinicopathological features of non-small cell lung cancer patients and its impact on survival: A systematic review and meta-analysis. Thorac Cancer 8: 203-213, 2017.

16. Zhu X, Li Z, Li T, Long F, Lv Y, Liu L, Liu X and Zhan Q: Osthole inhibits the PI3K/AKT signaling pathway via activation of PTEN and induces cell cycle arrest and apoptosis in esophageal squamous cell carcinoma. Biomed Pharmacother 102: 502-509, 2018.

17. Lim SL, Goh YM, Noordin MM, Rahman HS, Othman HH, Abu Bakar NA and Mohamed S: Morinda citrifolia edible leaf extract enhanced immune response against lung cancer. Food Funct 7: 741-751, 2016.

18. Wang C, Cheng Y, Liu H, Xu Y, Peng H, Lang J, Liao J, Liu H, Liu H and Fan J: Pectolinarigenin suppresses the tumor growth in nasopharyngeal carcinoma. Cell Physiol Biochem 39: 1795-1803, 2016.

19. Zhang T, Li S, Li J, Yin F, Hua Y, Wang Z, Lin B, Wang H, Zou D, Zhou Z, et al: Natural product pectolinarigenin inhibits osteosarcoma growth and metastasis via SHP-1-mediated STAT3 signaling inhibition. Cell Death Dis 7: e2421, 2016.

20. Livak KJ and Schmittgen TD: Analysis of relative gene expression data using real-time quantitative PCR and the 2(-Delta Delta C(T)) method. Methods 25: 402-408, 2001.

21. Lu C, Wang H, Chen S, Yang R, Li H and Zhang G: Baicalein inhibits cell growth and increases cisplatin sensitivity of A549 and H460 cells via miR-424-3p and targeting PTEN/PI3K/Akt pathway. J Cell Mol Med 22: 2478-2487, 2018.

22. Yu C, Zhang B, Li YL and Yu XR: SIX1 reduces the expression of PTEN via activating PI3K/AKT signal to promote cell proliferation and tumorigenesis in osteosarcoma. Biomed Pharmacother 105: 10-17, 2018.

23. Li Z, Hong S and Liu Z: LncRNA LINC00641 predicts prognosis and inhibits bladder cancer progression through miR-197-3p/KLF10/PTEN/PI3K/AKT cascade. Biochem Biophys Res Commun 503: 1825-1829, 2018.

24. Liu J, Xing Y and Rong L: miR-181 regulates cisplatin-resistant non-small cell lung cancer via downregulation of autophagy through the PTEN/PI3K/AKT pathway. Oncol Rep 39: 1631-1639, 2018.

25. Jing X, Cheng W, Wang S, Li P and He L: Resveratrol induces cell cycle arrest in human gastric cancer MGC803 cells via the PTEN-regulated PI3K/Akt signaling pathway. Oncol Rep 35: 472-478, 2016

26. Matsuda S, Nakagawa Y, Kitagishi Y, Nakanishi A and Murai T: Reactive oxygen species, superoxide dimutases, and PTEN-p53-AKT-MDM2 signaling loop network in mesenchymal stem/stromal cells regulation. Cells 7: E36, 2018.

27. de Assis LV and Isoldi MC: The function, mechanisms, and role of the genes PTEN and TP53 and the effects of asbestos in the development of malignant mesothelioma: A review focused on the genes' molecular mechanisms. Tumour Biol 35: 889-901, 2014. 
28. He M, Jiang L, Li B, Wang G, Wang J and Fu Y: Oxymatrine suppresses the growth and invasion of MG63 cells by up-regulating PTEN and promoting its nuclear translocation. Oncotarget 8: 65100-65110, 2017.

29. Oxnard GR, Hu Y, Mileham KF, Husain H, Costa DB, Tracy P, Feeney N, Sholl LM, Dahlberg SE, Redig AJ, et al: Assessment of resistance mechanisms and clinical implications in patients with EGFR T790m-positive lung cancer and acquired resistance to osimertinib. JAMA Oncol: Aug 2, 2018 (Epub ahead of print).

30. Dai Z, Wang L, Wang X, Zhao B, Zhao W, Bhardwaj SS, Ye J, Yin Z, Zhang J and Zhao S: Oxymatrine induces cell cycle arrest and apoptosis and suppresses the invasion of human glioblastoma cells through the EGFR/PI3K/Akt/mTOR signaling pathway and STAT3. Oncol Rep 40: 867-876, 2018.

31. Li W, Yu X, Ma X, Xie L, Xia Z, Liu L, Yu X, Wang J, Zhou H, Zhou X, et al: Deguelin attenuates non-small cell lung cancer cell metastasis through inhibiting the CtsZ/FAK signaling pathway. Cell Signal 50: 131-141, 2018.

32. Koundouros $\mathrm{N}$ and Poulogiannis G: Phosphoinositide 3-kinase/Akt signaling and redox metabolism in cancer. Front Oncol 8: 160, 2018.
33. Liao K, Yong CW and Hua K: SB431542 inhibited cigarette smoke extract induced invasiveness of A549 cells via the TGF-ß31/Smad2/MMP3 pathway. Oncol Lett 15: 9681-9686, 2018.

34. Wu C, Zhu X, Liu W, Ruan T, Wan W and Tao K: NFIB promotes cell growth, aggressiveness, metastasis and EMT of gastric cancer through the Akt/Stat3 signaling pathway. Oncol Rep 40: $1565-1573,2018$

35. Xing Y, Liu Y, Liu T, Meng Q, Lu H, Liu W, Hu J, Li C, Cao M, Yan S, et al: TNFAIP8 promotes the proliferation and cisplatin chemoresistance of non-small cell lung cancer through MDM2/p53 pathway. Cell Commun Signal 16: 43, 2018.

This work is licensed under a Creative Commons Attribution-NonCommercial-NoDerivatives 4.0 International (CC BY-NC-ND 4.0) License. 